\title{
What public health strategies are needed to reduce smoking initiation?
}

\author{
John P Pierce, ${ }^{1}$ Victoria M White, ${ }^{2}$ Sherry L Emery ${ }^{3}$
}

\begin{abstract}
${ }^{1}$ Moores UCSD Cancer Center, University of California, San Diego, La Jolla, California, USA ${ }^{2}$ Centre for Behavioural Research in Cancer, The Cancer Council Victoria, Victoria,

Australia

${ }^{3}$ Institute for Health Research and Policy, University of Illinois at Chicago, Chicago, Illinois, USA
\end{abstract}

\section{Correspondence to}

Dr John P Pierce, Cancer Prevention and Control Program, Moores UCSD Cancer Center, University of California, San

Diego, La Jolla, California 92093-0901, USA:

jppierce@ucsd.edu

Received 6 July 2011 Accepted 2 December 2011

\section{ABSTRACT}

Smoking initiation is a key behaviour that determines the future health consequences of smoking in a society. There is a marked difference in smoking patterns around the world, driven by initiation rates. While a number of high-income countries have seen smoking prevalence decline markedly from peak, many low-income and middle-income countries appear to still be on an upward trend. Unlike cessation where changes are limited by nicotine dependence, rates of smoking initiation can change rapidly over a short time span. Interventions that can be effective in achieving this include increases in the price of tobacco products, mass media anti-smoking advertising, smoke-free policies, smoking curricula in schools, restrictions on marketing opportunities for the tobacco industry as well as social norms that lead to restrictions on adolescents' ability to purchase cigarettes. Comprehensive tobacco control programmes that aim to denormalise smoking behaviour in the community contain all of these interventions. Rapid reductions in smoking initiation in adolescents have been documented in two case studies of comprehensive tobacco control programmes in California and Australia. Consistent and inescapable messages from multiple sources appear to be key to success. However, the California experience indicates that the rapid decline in adolescent smoking will not continue if tobacco control expenditures and the relative price of cigarettes are reduced. These case studies provide strong additional evidence of the importance of countries implementing the provisions of the Framework Treaty on Tobacco Control.

\section{INTRODUCTION}

During the 20th century, cigarettes became the predominant form of tobacco use across the world and ushered in the global lung cancer epidemic. ${ }^{1}$ In Western high-income countries, public health approaches to reduce the health consequences of tobacco use started in the 1960s and have focused primarily on cigarette smoking. ${ }^{2}$ Almost 50 years later, it is time to review tobacco control and tobacco industry strategies that are focused on the initiation of cigarette smoking.

Lopez and colleagues ${ }^{3}$ described the different patterns of diffusion of cigarette smoking across world cultures, noting the early adoption of Western high-income countries and the slower adoption in many lower-income and middleincome countries. From tables 1 and 2, three groups of countries are worth noting. Countries in Western Europe, North America and Australasia were early adopters of smoking, and experienced a rapid increase to a high per-capita cigarette consumption in the beginning of the 20th century that peaked in the $1960 \mathrm{~s}^{4}$ Since the start of tobacco control programmes, these countries have experienced dramatic declines (over $70 \%$ in the USA) from that peak consumption. Table 1 shows that in 2006, male smoking prevalence in these countries was generally in the $21 \%$ to $30 \%$ category, considerably below those with the highest smoking prevalence such as the Russian Federation, Greece and Indonesia. Similarly for women, smoking prevalence in these early adopter countries has declined to the $10 \%$ to $20 \%$ level (table 2 ). A second large group of countries (eg, China, Malaysia and Thailand) has a low female smoking prevalence, which is in stark contrast to the male smoking prevalence. Hitchman and Fong ${ }^{5}$ have noted that many countries in this group have low levels of female gender empowerment (measured by participation in economics and politics including decision-making roles). The tobacco industry has a history of adeptly linking cigarette smoking to the female empowerment movement that occurred in earlier years in high-income countries. ${ }^{6}$ There appears to be a third small group (eg, Ghana, Ethiopia) where cigarette smoking may have never been a common behaviour for either gender.

Across high-income and low-income countries, the process of adopting smoking as a socially normative behaviour has typically started among the higher educated groups; in countries where reductions have occurred, this group has also been the first to reduce smoking. ${ }^{7} 8$ Indeed, the prevalence of smoking in medical students, compared to the population, can be a reasonable marker of the current strength of tobacco control. ${ }^{4} 9$ Recently, Sreeramareddy et al (2010) noted that over $20 \%$ of female medical students from Bangladesh, Pakistan, Malaysia and Nepal had experimented with smoking. ${ }^{10}$ This is significantly higher than adult female smoking prevalence, and suggests that these countries may need to implement additional effective strategies if they are to avoid the general equilibration of smoking rates across genders that is present in many high-income countries. ${ }^{11}$

\section{THE PROCESS OF SMOKING INITIATION}

It usually takes time for an individual to become a smoker, allowing for several opportunities for tobacco control interventions that can either focus on the prevention of experimentation or progression to higher smoking levels. There are identifiable cognitions (curiosity, weakening of intention not to smoke) that predict future smoking, whether it be first experimentation or progression to a higher level of smoking experience (eg, puffer, experimenter, to occasional and then regular smoker, 
Table 1 Smoking prevalence among men aged $\geq 15$ years of age in 2006, WHO Health Statistics

\begin{tabular}{|c|c|}
\hline $\begin{array}{l}\text { Prevalence } \\
\text { category }\end{array}$ & Country \\
\hline$>50 \%$ & $\begin{array}{l}\text { Russian Federation, Ukraine, Greece, Indonesia, China, Tunisia, } \\
\text { Philippines, Malaysia, Turkey }\end{array}$ \\
\hline $41 \%$ to $50 \%$ & $\begin{array}{l}\text { Cambodia, Bangladesh, Romania, Hungary, Vietnam, Thailand, Cuba, } \\
\text { Syria, Kazakstan, Myanmar, Chile }\end{array}$ \\
\hline $31 \%$ to $40 \%$ & $\begin{array}{l}\text { Mexico, Nepal, Pakistan, Czech Republic, Argentina, India, } \\
\text { Zimbabwe, Sri Lanka, Venezuela, Morocco, France, Germany, Spain, } \\
\text { Italy, Finland }\end{array}$ \\
\hline $21 \%$ to $30 \%$ & $\begin{array}{l}\text { Iran, Poland, Iraq, South Africa, Yemen, Algeria, Sudan, Egypt Kenya, } \\
\text { USA, Guatemala, Ecuador, Saudi Arabia, Malawi, Mozambique, } \\
\text { Zambia, Burkina Faso, Australia, Canada, UK, Norway }\end{array}$ \\
\hline $11 \%$ to $20 \%$ & $\begin{array}{l}\text { Brazil, Uganda, Senegal, Mali, Dominican Republic, Cote D'ivorie, } \\
\text { Nigeria, Sweden }\end{array}$ \\
\hline$<11 \%$ & Ghana, Ethiopia \\
\hline
\end{tabular}

etc). ${ }^{12}{ }^{13}$ In high-income countries such as the USA, there is good evidence that experimentation generally occurs between the ages of 10-24 years. ${ }^{14}$ While some cultures have reported smoking at an earlier age, there is little evidence to suggest an uptake pattern in which never smokers start the initiation process after the age of 24 years. Early experimentation and use is nearly always undertaken in a social context, which emphasises the importance of interventions focused on denormalising smoking. As there is considerable change in friendship groups during adolescence, high-risk cognitions may lead an adolescent to seek out friends who offer the opportunity to smoke. ${ }^{15}$ Certainly, in almost all studies, having peers who smoke is a strong predictor of future adult smoking. ${ }^{16}$

\section{THE ROLE OF THE TOBACCO INDUSTRY IN ENCOURAGING INITIATION}

Industry documents obtained as part of the legal process have demonstrated that tobacco companies use a business model that is focused on maintaining or increasing new users of their products, even if this means targeting adolescents. This is achieved by marketing products that promote adolescent cognitions that increase the probability of experimentation and continued use. ${ }^{17} 18$ Over the past century, cigarettes have become one of the most heavily marketed products around the world. Tobacco companies have created distinct lifestyle images associated with different brands, and their marketing strategies include package design, product placement, advertising, promotional activities and pricing. In 2008, the US National Cancer Institute published a major review of the evidence that

Table 2 Smoking prevalence among women aged $\geq 15$ years of age in 2006, WHO Health Statistics

\begin{tabular}{ll}
\hline $\begin{array}{l}\text { Prevalence } \\
\text { category }\end{array}$ & Country \\
\hline $30 \%$ to $40 \%$ & $\begin{array}{l}\text { Greece, Poland, Hungary, Chile } \\
\text { Cuba, Nepal, Russian Federation, Czech Republic, Venezuela, } \\
\text { Argentina, Romania, Ukraine, France, Germany, Spain, Sweden, } \\
\end{array}$ \\
$\begin{array}{l}\text { Norway, Finland } \\
10 \% \text { to 20\% }\end{array}$ & $\begin{array}{l}\text { Turkey, USA, Myanmar, Dominican Republic, Mexico, Philippines, } \\
\text { Brazil, Burkina Faso, Australia, Canada, UK, Italy }\end{array}$ \\
$3 \%$ to 10\% & $\begin{array}{l}\text { South Africa, Kazakhstan, Tunisia, Cambodia, Pakistan, Yemen, } \\
\text { Ecuador, Iran, Malawi, Indonesia, Zambia, Zimbabwe, Uganda, }\end{array}$ \\
& $\begin{array}{l}\text { Guatemala, India, Bangladesh, China, Saudi Arabia, Iraq, } \\
\text { Mozambique, Sudan }\end{array}$ \\
& Malaysia, Mali, Vietnam, Cote D'ivorie, Sri Lanka, Kenya, Thailand, \\
& Egypt, Senegal, Nigeria, Ethiopia, Ghana, Algeria, Morocco \\
\hline
\end{tabular}

concluded that tobacco product marketing is causally associated with tobacco usage, particularly by the young. ${ }^{19}$

Marketing $^{18}$ and psychology ${ }^{20}$ theories both suggest that there is a hierarchy of effects from persuasive communications. Initially, individuals need to be exposed to a communication, and a proportion will attend to the message. Of those who attend to the message, a portion will like it, maybe as much as to indicate that the message is one of their favourites. Some will identify so strongly with the image that they will be prepared to wear it on clothing or use imprinted accessories. ${ }^{21}$ Young teens who have a favourite cigarette brand are almost 50\% more likely to smoke 6 years later, and those prepared to wear or use a tobacco-branded item were $84 \%$ more likely to be adult smokers. $^{22}$

Countries have implemented restrictions on tobacco marketing practices; however, in every case, restrictions have been implemented gradually so that a variety of marketing channels still remained open to the tobacco industry. In response, the industry increased its overall expenditure on marketing ${ }^{23}$ and companies have been innovative with their marketing strategies. In the USA, after the 1999 restrictions on advertising targeting young people, the tobacco industry shifted their marketing dollars to young adult venues ${ }^{24}$ and point-ofsale advertising. ${ }^{25}$ There was a marked increase in the quantity of in-store advertising, ${ }^{26}$ especially among those stores frequented by adolescents. ${ }^{27}$ This shift led to an increase in adolescent recall of in-store advertising; a longitudinal study has found that those who recall in-store exposure were more likely to start smoking. ${ }^{28}$

The cigarette packet design is also part of the brand's marketing as it provides key components of the brand image from which all other marketing is built. The pack colours, graphic elements, proportioning, texture, materials and typography promote the brand's image. ${ }^{29}$ Tobacco industry documents reveal that a key strategy for promoting initiation is to convince adolescents that the 'psychological benefits' that are associated with the brand will help them deal with the emotional challenges of adolescence. ${ }^{30}$

\section{TOBACCO INDUSTRY-SPONSORED 'PREVENTION' EFFORTS}

Starting in the 1980s, tobacco companies have launched programmes in at least 26 countries ostensibly to prevent smoking initiation among the school-aged population. However, internal documents show that tobacco industry leaders viewed such initiatives as a way to prevent or delay legislation, regulation, or even threatened litigation. ${ }^{31}$ In addition, by controlling the prevention intervention, the tobacco industry could ensure that more effective strategies were suppressed. In 1990, Philip Morris was temporarily successful in convincing the California Department of Education to distribute a tobacco industry sponsored 'anti-smoking' set of materials to schools. ${ }^{31}$

In 1998, Philip Morris USA created its own Department of Youth Smoking Prevention with the stated objective of helping to prevent adolescent smoking. Through 2010, they made payments of over US $\$ 55$ billion to numerous USA states to disseminate their projects that included the 'We Card' programme in retail stores, an online "Raising Kids Who Don't' Smoke" parent resource series and selected 'anti-smoking' school curricula. $^{32}$ A number of these programmes were evaluated independently; it was concluded that none of the programmes were effective at preventing teen smoking, with some showing evidence that the programmes encouraged smoking. ${ }^{19}$ In the late 1990s, an evaluation of illegal underage sales in retail stores in 
California demonstrated that stores with 'We Card' and other tobacco industry signs had considerably higher sales to minors than stores with government signs. ${ }^{33}$

Following the 1998 Master Settlement Agreement, Philip Morris and Lorillard launched substantial television advertising campaigns, targeted at youth and adults, with the putative message of preventing youth smoking. In contrast to government sponsored anti-smoking TV adverts, higher youth exposure to these tobacco industry adverts was associated with reduced anti-smoking attitudes and beliefs, and a higher probability of smoking among USA high school youth. ${ }^{34}$ In California, advertising messages such as adults lecturing teens were nominated as a favourite anti-smoking advertisement by a number of adults over the age of 55 years. ${ }^{35}$ This suggests that this may have been the real target audience with a goal of improving company image in the community as a way to prevent strengthening public support for anti-smoking interventions.

\section{TOBACCO CONTROL INTERVENTIONS}

There is substantial literature on interventions aimed at reducing smoking initiation, mainly from high-income countries. These interventions include school programmes, increasing price through excise tax increases, large graphic warning labels on packages, restricting the tobacco industry's ability to advertise, tobacco control mass media programmes, smoke-free policies and restricting the ability of minors from purchasing tobacco products. It is important to note that the effectiveness of an overall approach is more than the sum of the effectiveness of the independent strategies. In Australia ${ }^{36-38}$ and California $^{2} 39$ comprehensive community-wide programmes using multiple strategies have documented large declines in smoking initiation. The key goal of such programmes is the denormalisation of tobacco in the entire community. ${ }^{40} 41$

\section{SCHOOL INTERVENTIONS}

School programmes are often one of the first approaches mentioned in efforts to denormalise tobacco. Early training might be able to 'inoculate' students against influences encouraging them to experiment with smoking, or social skills training/practice could help them resist temptations from peers to smoke. A Cochrane review ${ }^{42}$ identified 133 studies of school interventions of which 94 had the most rigorous design (ie, randomised trial). The authors concluded that evidence for the effectiveness of these interventions was mixed with effects being limited to short-term outcomes only. They focused on one 'high quality' trial that had a particularly rigorous measurement protocol $^{43}$ and noted that the school intervention had no effect. However, this study did not demonstrate a between-group difference as a result of the educational intervention. Without such a difference, it would be impossible for the study design to demonstrate an effect. Others have also reviewed the 30-year history of studies and concluded that adequate evidence exists to recommend ongoing implementation of school-based tobacco prevention interventions. ${ }^{44}$ However, confidence of tobacco control advocates in school programmes was shaken when Philip Morris chose to promote the Lifeskills Training Program, a 6 th grade intervention programme that had been designated as an effective programme by the Centers for Disease Control and Prevention (CDC). ${ }^{45}$

One of the problems with this research is that very few of the interventions are up-to-par with standards necessary for quality comprehensive education. The USA National Health Education Standards ${ }^{46}$ require that students: (a) comprehend the health risks, (b) analyse the influences of family, peers, culture and media on usage patterns, (c) develop interpersonal skills to resist temptations and (d) practice goal setting and decision making skills to protect against use. They recommend that this be included in the curriculum of every school year (kindergarten through grade 12). The CDC supports such a curricula approach, but indicates that it is not enough. In addition, schools need to (a) have explicit tobacco control policies, (b) have appropriate teacher training, (c) involve parents and families, (d) support cessation for teachers, staff and students and (e) regularly evaluate performance. The only way schools can reach all of the above goals (especially with limited budgets) is a comprehensive approach in which preventing initiation is a high public priority and significant progress has been made on denormalising tobacco use in the broader community. Supporting this, a recent European study ${ }^{47}$ found that disciplining students for a smoking infraction was only associated with lower prevalence when teachers and parents were non-smokers and supportive of the programme.

\section{WARNING LABELS AND PLAIN PACKAGING}

Warning labels on cigarette packs, which were introduced in the USA in 1966, are often one of the first tobacco control initiatives. ${ }^{48}$ Whereas obscure text-only warnings appear to have little impact, recently implemented prominent graphic health warnings on packages have been demonstrated to serve as a key source of health information for smokers and non-smokers, increasing health knowledge and perceptions of risk. ${ }^{49}$ Prominent pictorial warning labels have been found to lower smoking intentions among adolescent smokers and non-smokers. ${ }^{50}$

Australia is the first country to attempt to counter the tobacco industry's package advertising and require that cigarette packages do not include any tobacco marketing (ie, plain packaging). Formative research on plain packaging among Australian youth found that they would be less likely to purchase the product and more likely to take the health warnings seriously. ${ }^{51}$ Should the Australian government successfully defend its new law in 2012, this will result in a major demonstration project that will be carefully followed by the tobacco industry and tobacco control advocates across the world.

\section{INCREASING THE PRICE OF CIGARETTES TO PREVENT INITIATION}

Price elasticity refers to the relationship between price and demand for a particular consumer product. In the context of adolescent smoking, there is significant literature on the price elasticity of youth demand for cigarettes. Key studies in the early years of USA tobacco control interventions estimated that price elasticity of adolescent demand for cigarettes was -1.44 ; in other words, for every US $\$ 0.10$ increase in the price/pack of cigarettes, youth smoking declines by approximately $14 \% .{ }^{52}$ While the price of cigarettes does not appear to influence whether or not an adolescent experiments with cigarettes, ${ }^{53}$ there is strong evidence that price matters once teens progress as far as buying their own cigarettes. ${ }^{54}$

However, many USA states dramatically increased state cigarette taxes after 1999 and some recent studies have not found this price increase associated with the expected high adolescent elasticity. Nonnemaker et al (2011) found a significant but smaller effect of tax and price on youth smoking initiation. ${ }^{55}$ In this study, higher price responsiveness among minorities explained a lot of the price elasticity. It may be that price elasticity is influenced by the number of tobacco control 
strategies implemented in the community. A recent European study examined the influence of price along with several other tobacco control policies on smoking participation and did not find the expected association between increased price and lower smoking. ${ }^{56}$ However such a study is an outlier in the literature. A recent Australian study found that increases in the price of cigarettes over a 12-month period were associated with lower likelihood of smoking after adjusting for other policy factors including point-of-sale advertising restrictions, clean indoor air laws and tobacco control funding.

\section{MASS MEDIA IN TOBACCO CONTROL PROGRAMIMES}

There have been numerous studies of the role of mass media counter-advertising campaigns in preventing smoking initiation. ${ }^{58}$ These have included randomised as well as interrupted time series studies of smoking, before and after implementation of an anti-smoking campaign. Media channels commonly used for tobacco control advertising include television, radio, print and billboards. Themes that are commonly used in this advertising include health consequences of smoking, tobacco industry manipulation, dangers of secondhand smoke (SHS) and the declining social acceptability of smoking. As the frequency of exposures over time is critical to effectiveness, paid television advertisements tend to be the most costly component of a comprehensive tobacco control programme. The National Cancer Institute's report ${ }^{19}$ on the role of media in tobacco use concluded that there is a consensus that advertising that arouses a strong negative emotion is more likely to be associated with changes in youth attitudes about tobacco (social norms) and lower smoking initiation compared to other advertising messages. However, the largest effects are present when antismoking media campaigns are combined with school and/or community-based programmes within comprehensive tobacco control programmes.

Adolescent receptivity (favourite advertisement, identification with brand logo etc) to counter-advertising is an important way of assessing the likely impact of media campaigns. In 2005 and 2008, Californians nominated their favourite anti-smoking advertisement; strong health consequences messages and those focused on the manipulative strategies of the tobacco industry were most salient to teens and young adults. ${ }^{35}$ However, while there is considerable willingness to name a favourite antismoking advertisement, there is no evidence to suggest that clothing with an anti-smoking brand logo is likely to be a popular dress item with adolescents. Analyses of California surveys suggest that having a favourite anti-smoking advertisement will reduce the probability that a favourite cigarette advertisement will lead to future smoking. However, mass media strategies are very costly. As media channels have proliferated in recent years (especially with widespread availability with the internet), the cost of traditional mass media programmes has increased dramatically and most tobacco control programmes need to limit their level of commitment to this area and carefully choose channels.

\section{SMOKE-FREE POLICIES}

The health consequences of SHS became evident in the 1980s and, in 1992, the Environmental Protection Agency of the USA categorised SHS as a class A carcinogen. ${ }^{59}$ Local jurisdictions in the USA responded by increasing the number of laws and ordinances requiring smoke-free workplaces and in 1994, California passed a state law. Evidence of the effectiveness of this policy in reducing SHS exposure led to its inclusion in the unprecedented WHO treaty, the Framework Convention for Tobacco Control (FCTC). As a result of this treaty, smoke-free laws are expected to increase significantly over the next few years. The introduction of strong smoke-free regulations in public spaces such as restaurants and cafes contributes to the denormalisation of tobacco in a community, ${ }^{60}$ and reduces the likelihood of an adolescent becoming a regular smoker. ${ }^{61}$ The implementation of smoke-free workplace and public space laws has been associated with the voluntary adoption of smoke-free homes, which has resulted in increased protection of children from exposure to SHS. ${ }^{61} 62$ There are numerous cross-sectional surveys that have demonstrated the association between smokefree homes and lower initiation rates among teens ${ }^{63}$ although these results are awaiting confirmation in ongoing longitudinal studies. $^{61}$

\section{RESTRICTING ACCESS TO CIGARETTES BY MINORS}

Perhaps the most controversial intervention to reduce smoking initiation are policies focused on restricting adolescents' access to purchase cigarettes. ${ }^{24}$ Many USA states had laws dating back to the early 20 th century (mostly not enforced) that limited purchase of cigarettes to people over the age of 18 years. The California experience ${ }^{64}$ has demonstrated that, as cigarette smoking becomes increasingly denormalised, adults are more likely to express opinions that enforcement of sales to minors laws are inadequate. However, adolescent smokers are adept at ensuring that these laws do not limit their ability to obtain cigarettes by knowing which stores have lax monitoring or by paying older teens to purchase for them. ${ }^{65}$ Indeed, most experimenters and occasional smokers obtain their cigarettes from social sources. ${ }^{66}$ While these laws may not influence an adolescent's ability to obtain cigarettes, significant declines in the proportion of never smokers who thought it was easy to get cigarettes was associated with enforcement of the laws. ${ }^{64}$

\section{CASE STUDIES}

Summarised below are two case studies of long-term smoking prevention programmes which have had detailed evaluations. In each case, a major decline in smoking initiation has been documented since 1996. Both examples involve a large population in which tobacco control policy required government policy and funding.

\section{Case study 1: California}

In the USA, a federal law banned tobacco advertising on the broadcast media in 1971 . There were no additional national restrictions on tobacco marketing until 1998 when the state attorneys general settled their lawsuits against the tobacco companies. The resulting Master Settlement Agreement significantly restricted marketing that could be construed as targeting minors. ${ }^{23}$ Weak warning labels were implemented in 1966 without any significant upgrade until 2011.

California was one of the first states to implement tobacco control initiatives ${ }^{2}$ and, although these were unfunded for over 20 years, these efforts resulted in a differential decline (compared to the rest of the nation) in smoking across birth cohorts. Starting in 1990, California increased this effort by introducing a comprehensive programme focused on changing social norms regarding tobacco use, using monies from a population-wide voter initiative that increased the excise tax on tobacco. ${ }^{40}$ Although per capita funding levels fluctuated considerably over time, interventions included an ongoing mass media antismoking advertising campaign, and local programmes that (a) 
countered pro-tobacco influences in the community, (b) reduced exposure to SHS, (c) reduced availability of tobacco products for minors and (d) increased services to help smokers successfully quit. In addition, the Department of Education had its own funding from this initiative. ${ }^{67}$ In 1996, all K-12 grade schools were required by law to have smoke-free campuses. After 1996, two-thirds of school funding was allocated to local educational agencies provided that they fully implemented the tobacco-free school policy. This provided funding for programmes in grades 6-12 through a competitive application process for tobaccospecific student instruction, reinforcement activities, special events, intervention and cessation programmes for students.

Once every decade since the 1960s, California increased excise taxes to raise cigarette prices above those of the rest of the nation, a factor associated with California's more rapid decline in cigarette consumption. ${ }^{2}$ However, the last such price increase was in 1999 and, from 2005 to 2011, cigarettes have been cheaper in California than the rest of the nation. ${ }^{2}$ In 1994, California passed the world's first smoke-free workplace law, which included bars and taverns. Further, in 1996, the tobacco control programme implemented a unique and apparently effective programme to enforce the federal ban on sale of cigarettes to minors. ${ }^{68}$

These activities were associated with social norm change at the population level and, in conjunction with the innovative school education programme, were associated with halving the proportion of California youth who smoked in the prior month between 1996 and 2004 (from 28\% in 10th graders). ${ }^{69}$ California then led the nation with the lowest school smoking prevalence in 2004 at $13 \% .^{70}$ This reduction in smoking prevalence resulted from a reduction in experimentation in each younger birth cohort, ${ }^{71}$ which was achieved by an apparent inoculation effect on adolescents, preventing the development of the known risk factors for smoking. ${ }^{72}$ However, these large year-to-year reductions in California smoking were not maintained after 2004. This loss of effect cannot be attributed to changes in school curricula or policy, declines in the effectiveness of SHS policies, differences in enforcement of laws restricting teen purchase of cigarettes, or to warning labels on the cigarette pack. What did change was the level of tobacco control expenditures and the relative price of cigarettes. ${ }^{2}$ The price issue may have been exacerbated by evidence that tobacco industry marketing expenditures are often targeted to states with tobacco control programmes.

\section{Case study 2: Australia}

The Australian federal government banned direct tobacco marketing from the electronic media in 1976 and from the print media in 1991. Large text-based health-warning labels were required on all cigarette packs in 1995. In 2006, these were updated to include large and graphic pictures of the health consequences of smoking, with the health warnings taking up $90 \%$ of the back of the pack and $30 \%$ of the front. ${ }^{50}$ In 2006 , the last remnants of allowable tobacco industry sponsorship of sporting and cultural events were phased out.

State governments in Australia introduced the first community-wide comprehensive tobacco control programmes, and all states had such programmes by the mid 1990s. ${ }^{36} 73$ In 1987, the state of Victoria was the first to use a tobacco tax to fund their tobacco control programme, and this model was subsequently replicated in several other Australian states. Mass media advertising was a key component of tobacco control programmes, and Australia was the first to use emotionally strong health consequences advertising. ${ }^{74}$ In addition to mass media, these programmes have had a strong advocacy component and state governments have legislated restrictions on youth access to cigarettes, clean indoor air and restrictions on the promotion of tobacco products including at point-of-sale. Recent progress in the latter area includes state governments banning the display of cigarettes at point-of-sale.

Since the early 1990s, state government schools have had smoke-free buildings, with these restrictions extending to school ground campuses during the 2000s. The last state restricting smoking on school campuses occurred in 2009. Smoking prevention activity has been included in the curriculum of primary and secondary schools across Australia since the early 1990s. ${ }^{75}$

Increasing the price of tobacco has also been a focus of Australian tobacco control programmes and advocates. Taxation on tobacco products became the sole remit of the federal government in 1997, and in 1999, the government changed the system of levying excise and customs duty on cigarettes from a per-weight of tobacco basis to a per-stick system. This and other taxation changes in 1999 increased the average price of cigarettes by $30 \%$ to $40 \%$. However, there has been little real increase in the price of cigarettes since 2001. ${ }^{75}$

The level of funding for tobacco control programmes in Australia has fluctuated substantially over the past 25 years. The period with the lowest funding levels (1990-1996) was the time when adolescent smoking increased, ${ }^{76}$ leading Hill et al (1998) to conclude that smoking prevalence may respond directly to tobacco control funding levels. ${ }^{77}$ In 1997, Australia introduced a nationally coordinated approach to tobacco control that included an increase in funding for tobacco control activities from AUS\$0.63 in 1996 to peak at AUS\$1.63 per capita in 2002 (in 2005 AUS\$). Smoke-free workplace laws were introduced in Australian states in the mid to late 1990s and quickly disseminated in the 2000s, with estimates suggesting that smoke-free laws influenced $96 \%$ of the Australian population by $2008 .{ }^{58}$

Past month smoking prevalence among Australian secondary students aged 12 to 17 years decreased from a national average of $26 \%$ in 1996 to $13 \%$ in $2005^{57}$ and $10 \%$ in $2008 .^{78}$ The major reductions in smoking prevalence have been associated with higher funding levels to tobacco control programmes, higher cigarette prices and greater restrictions on smoking in public spaces. ${ }^{57}$

\section{SUMMARY}

There is strong evidence from these two case studies that comprehensive tobacco control programmes are able to denormalise cigarette smoking and have a dramatic impact in reducing the proportion of adolescents who start to smoke. Both of these case studies implemented multiple interventions; both had powerful mass media anti-smoking campaigns, increased the price of cigarettes, and had school programmes, SHS policies and restrictions on youth access to cigarettes. In addition, both had significant restrictions on tobacco marketing practices. Australia had much stronger warning labels on cigarette packets than California. The California case study, however, demonstrates that a sharp decline in youth prevalence will not continue if there is a major drop in tobacco control expenditures and a reduction in the relative price of cigarettes.

\section{RECOMMENDATIONS}

Nations need to implement the comprehensive tobacco control strategies aimed at smoking initiation that are outlined in the WHO's Framework Convention on Tobacco Control. These 


\section{What this paper adds}

This paper notes the evidence on the effectiveness of each individual tobacco control intervention.

- There are two geographic locations (California and Australia) with major documented declines in smoking initiation in the past 20 years. Each has achieved this effect using comprehensive interventions involving multiple effective interventions.

- This evidence provides nations with a strong rationale for implementing all the elements of the Framework Convention on Tobacco Control.

include: raising excise taxes in order to deincentivise smoking and raise revenue for tobacco control, implementing policies to protect their populations from SHS, introduce laws and regulations that reduce the capability of the tobacco industry to use mass marketing strategies to promote use of their products, and laws/regulations that require vivid pictorial warnings on cigarette packages. Future research needs to focus on evidence that demonstrates that introduction of harm reduction products does not lead to an increase in smoking initiation rates and on developing the evidence base that removing advertising from cigarette packages leads to declines in initiation rates.

Funding This study was funded by the University of California Tobacco Related Disease Research Program grants 18CA-0134, 18ST-0202 and 19ST-0181.

Competing interests None.

Provenance and peer review Commissioned; externally peer reviewed.

\section{REFERENCES}

1. Doll R. Evolution of knowledge of the smoking epidemic. In: Boyle P, Gray N, Henningfield JE, et al, eds. Tobacco Science, Policy, and Public Health. 2nd edn. Oxford: Oxford University Press, 2010:1-12.

2. Pierce JP, Messer K, White MM, et al. Forty years of faster decline in cigarette smoking in California explains current lower lung cancer rates. Cancer Epidemiol Biomarkers Prev 2010;19:2801-10.

3. Lopez AD, Collishaw NE, Piha T. A descriptive model of the cigarette epidemic in developed countries. Tob Control 1994;3:242-7.

4. Pierce JP. Progress and problems in international public health efforts to reduce tobacco usage. Annu Rev Public Health 1991;12:383-400.

5. Hitchman SC, Fong GT. Gender empowerment and female-to-male smoking prevalence ratios. Bull World Health Organ 2011;89:195-202.

6. Pierce JP, Lee L, Gilpin EA. Smoking initiation by adolescent girls, 1944 through 1988. An association with targeted advertising. JAMA 1994;271:608-11.

7. Pierce JP, Fiore MC, Novotny TE, et al. Trends in cigarette smoking in the United States. Projections to the year 2000. JAMA 1989;261:61-5.

8. Pierce JP, Gilpin E, Burns DM, et al. Does tobacco advertising target young people to start smoking? Evidence from California. JAMA 1991;266:3154-8.

9. Pierce JP, Gilpin E. Trends in Physicians' Smoking Behavior and Patterns of Advice to Quit. Rockville, MD: Smoking and Tobacco Control Monograph 5 National Cancer Institute NIH Publication, No 93-3693, 1993.

10. Sreeramareddy CT, Suri S, Menezes RG, et al. Self-reported tobacco smoking practices among medical students and their perceptions towards training about tobacco smoking in medical curricula: a cross-sectional, questionnaire survey in Malaysia, India, Pakistan, Nepal, and Bangladesh. Subst Abuse Treat Prev Policy 2010;5:29.

11. Fiore MC, Novotny TE, Pierce JP, et al. Trends in cigarette smoking in the United States. The changing influence of gender and race. JAMA 1989;261:49-55.

12. Choi WS, Gilpin EA, Farkas AJ, et al. Determining the probability of future smoking among adolescents. Addiction 2001;96:313-23.

13. Pierce JP, Distefan JM, Kaplan RM, et al. The role of curiosity in smoking initiation. Addict Behav 2005;30:685-96.

14. Pierce JP, Gilpin EA. Impact of over-the-counter sales on effectiveness of pharmaceutical aids for smoking cessation. JAMA 2002;288:1260-4.

15. Steinberg L. Adolescence. 6th edn. New York, NY: McGraw-Hill, 2002.

16. Bauman KE, Fisher LA, Bryan ES, et al. Antecedents, subjective expected utility, and behavior: a panel study of adolescent cigarette smoking. Addict Behav 1984:9:121-36.
17. Smith RE, Swinyard WR. Cognitive responses to advertising and trial: belief strength, belief confidence and product curiosity. J Advert 1988;17:3-14

18. Ray ML. Advertising and Communication Management. Englewood Cliffs, NJ: Prentice Hall, 1982

19. NCl. The Role of Mass Media in Promoting and Reducing Robacco Use. Tobacco Control Monograph no. 19. Bethesda, MD: US Department of health and Human Services, National Institutes of Health, National Cancer Institute, 2008. Report No.: 07-6242.

20. McGuire WJ. An Information Processing Model of Advertising Effectiveness. New York, NY: Behavioral and Management Science in Marketing, 1978.

21. Evans N, Farkas A, Gilpin $\mathrm{E}$, et al. Influence of tobacco marketing and exposure to smokers on adolescent susceptibility to smoking. J Nat/ Cancer Inst 1995:87:1538-45.

22. Gilpin EA, White MM, Messer K, et al. Receptivity to tobacco advertising and promotions among young adolescents as a predictor of established smoking in young adulthood. Am J Public Health 2007:97:1489-95.

23. Pierce JP, Gilpin EA. How did the Master Settlement Agreement change tobacco industry expenditures for cigarette advertising and promotions? Health Promot Pract 2004;5(Suppl 3):84S-90S

24. Ling PM, Glantz SA. Why and how the tobacco industry sells cigarettes to young adults: evidence from industry documents. Am J Public Health 2002:92:908-16.

25. Ruel E, Mani N, Sandoval A, et al. After the Master Settlement Agreement: trends in the American tobacco retail environment from 1999 to 2002. Health Promot Pract 2004:5(Suppl 3):99S-110

26. Feighery EC, Schleicher NC, Boley Cruz T, et al. An examination of trends in amoun and type of cigarette advertising and sales promotions in California stores, 20022005. Tob Control 2008;17:93-8.

27. Henriksen L, Feighery EC, Schleicher NC, et al. Reaching youth at the point of sale: cigarette marketing is more prevalent in stores where adolescents shop frequently. Tob Control 2004;13:315-18.

28. Henriksen L, Schleicher NC, Feighery EC, et al. A longitudinal study of exposure to retail cigarette advertising and smoking initiation. Pediatrics 2010;126:232-8.

29. DiFranza JR, Clark DM, Pollay RW. Cigarette package design: opportunities for disease prevention. Tob Induc Dis 2003;1:97-109.

30. Barton J, Chassin L, Presson CC, et al. Social image factors as motivators of smoking initiation in early and middle adolescence. Child Dev 1982;53:1499-511.

31. Landman A, Ling PM, Glantz SA. Tobacco industry youth smoking prevention programs: protecting the industry and hurting tobacco control. Am J Public Health 2002;92:917-30

32. Philip Morris USA. Helping Reduce Underage Tobacco Use. 2011. http://www. philipmorrisusa.com/en/cms/Responsibility/Helping_Nav/Helping_Reduce Underage Tobacco Use/Select Historical Programs/default.aspx

33. Cowling $\overline{\mathbf{D} W}$, Robins DM. Rate of illegal tobacco sales to minors varies by sign type in California. Am J Public Health 2000;90:1792-3.

34. Wakefield M, Terry-McElrath $\mathrm{Y}$, Emery $\mathrm{S}$, et al. Effect of televised, tobacco company-funded smoking prevention advertising on youth smoking-related beliefs, intentions, and behavior. Am J Public Health 2006;96:2154-60.

35. Al-Delaimy WK, White MM, Mills AL, et al. Two Decades of the California Tobacco Control Program: California Tobacco Survey, 1990-2008. La Jolla, CA: University of California, San Diego, 2010.

36. Pierce JP, Dwyer T, Frape G, et al. Evaluation of the Sydney "Quit. For Life" anti-smoking campaign. Part 1. Achievement of intermediate goals. Med J Aust 1986;144:341-4.

37. Dwyer T, Pierce JP, Hannam CD, et al. Evaluation of the Sydney "Ouit. For Life" antismoking campaign. Part 2. Changes in smoking prevalence. Med J Aust 1986;144:344-7.

38. Pierce JP, Macaskill P, Hill D. Long-term effectiveness of mass media led antismoking campaigns in Australia. Am J Public Health 1990:80:565-9.

39. Pierce JP, Gilpin EA, Emery SL, et al. Has the California tobacco control program reduced smoking? JAMA 1998;280:893-9.

40. Bal DG, Kizer KW, Felten PG, et al. Reducing tobacco consumption in California. Development of a statewide anti-tobacco use campaign. JAMA 1990;264:1570-4

41. Roeseler A, Burns D. The quarter that changed the world. Tob Control 2010;19 (Suppl 1):i3-15.

42. Thomas R, Perera R. School-based programmes for preventing smoking. Cochrane Database Syst Rev 2006;(3):CD001293.

43. Peterson AV Jr, Kealey KA, Mann SL, et al. Hutchinson Smoking Prevention Project: long-term randomized trial in school-based tobacco use prevention-results on smoking. J Natl Cancer Inst 2000;92:1979-91.

44. Dobbins $\mathbf{M}$, DeCorby $\mathrm{K}$, Manske $\mathrm{S}$, et al. Effective practices for school-based tobacco use prevention. Prev Med 2008;46:289-97.

45. Sussman S. Tobacco industry youth tobacco prevention Programming: a review. Prev Sci 2002;3:57-67.

46. NHES. National Health Education Standards: Achieving Excellence. Atlanta, GA: National health education standards, 2007.

47. Wiium N, Wold B. Actions taken by schools when tobacco policies are violated: associations with adolescent smoking prevalence. Scand J Psychol 2011:52:494-501.

48. USDHHS. Reducing the Health Consequences of Smoking: 25 Years of Progress. A Report of the Surgeon General. Rockville, MD: U.S. Dept. of Health and Human Services, Centers for Disease Control and Prevention, National Center for Chronic Disease Prevention and Health Promotion, Office on Smoking and Health, 1989. Report No.: (CDC) 89-8411.

49. Hammond D. Health warning messages on tobacco products: a review. Tob Control 2011;20:327-37 
50. White V, Webster B, Wakefield M. Do graphic health warning labels have an impact on adolescents' smoking-related beliefs and behaviours? Addiction 2008;103:1562-71.

51. Germain D, Wakefield MA, Durkin SJ. Adolescents' perceptions of cigarette brand image: does plain packaging make a difference? J Adolesc Health 2010;46:385-92.

52. Lewit EM, Coate D, Grossman M. The effects of government regulation on teenage smoking. J Law \& Econ 1981:24:545-69.

53. Emery S, White MM, Pierce JP. Does cigarette price influence adolescent experimentation? J Health Econ 2001;20:261-70.

54. Chaloupka F, Grossman M. Price, Tobacco Control Policies and Youth Smoking. Working paper \#5740. Cambridge, MA: National Bureau of Economic Research, 1996.

55. Nonnemaker JM, Farrelly MC. Smoking initiation among youth: the role of cigarette excise taxes and prices by race/ethnicity and gender. J Health Econ 2011;30:560-7.

56. Schnohr CW, Kreiner S, Rasmussen M, et al. The role of national policies intended to regulate adolescent smoking in explaining the prevalence of daily smoking: a study of adolescents from 27 European countries. Addiction 2008;103:824-31.

57. White VM, Warne CD, Spittal MJ, et al. What impact have tobacco control policies, cigarette price and tobacco control program funding had on Australian adolescents' smoking? Findings over a 15-year period. Addiction 2011;106:1493-502.

58. World Health Organization. WHO Report on the Global Tobacco Epidemic, 2011: Warning About the Dangers of Tobacco. Geneva, Switzerland: WHO, 2011.

59. USEPA. Respiratory Health Effects of Passive Smoking: Lung Cancer \& Other Disorders. Washington, DC: U.S. Environmental Protection Agency, Office of Research and Development, Office of Health and Environmental Assessment, 1992. 31 January 2007. Report no.: EPA/600/6-90/006F.

60. Hamilton WL, Biener L, Brennan RT. Do local tobacco regulations influence perceived smoking norms? Evidence from adult and youth surveys in Massachusetts. Health Educ Res 2008;23:709-22.

61. IARC. Evaluating the Effectiveness of Smoke-free Policies. Lyon: IARC Handbook of Cancer Prevention, Tobacco Control, 2009.

62. Akhtar PC, Haw SJ, Currie DB, et al. Smoking restrictions in the home and secondhand smoke exposure among primary schoolchildren before and after introduction of the Scottish smoke-free legislation. Tob Control 2009;18:409-15.

63. Pierce JP; (Working group Chair). Evaluating the Effectiveness of Smoke-free Policies. vol. 13. Lyon, France: IARC (International Agency for research on cancer prevention), Tobacco Control, 2009.

64. Al-Delaimy W, White MM, Trinidad DR. The California Tobacco Control Program: Can We Maintain the Progress? vol. 2. La Jolla, CA: University of California, San
Diego. http://www.cdph.ca.gov/programs/tobacco/Documents/CTCP-CTSVol.\%2021990-2005.pdf2008

65. Robinson J, Amos A. A qualitative study of young people's sources of cigarettes and attempts to circumvent underage sales laws. Addiction 2010;105:1835-43.

66. Robinson LA, Dalton WT 3rd, Nicholson LM. Changes in adolescents' sources of cigarettes. J Adolesc Health 2006:39:861-7.

67. Tobacco-Use Prevention Education Program Overview. California Department of education. http://www.cde.ca.gov/ls/he/at/tupeoverview.asp (accessed 15 Mar 2011).

68. Gilpin EA, White MM, White VM, et al. Tobacco Control Successes in California: A Focus on Young People, Results from the California Tobacco Surveys, 1990-2002. La Jolla, CA: University of California, San Diego, 2004.

69. Centers for Disease Control and Prevention. Cigarette use among high school students United states, 1991-2005. MMWR 2006;55:724-6.

70. Substance Abuse and Mental Health Services Administration Office of Applied Studies. State Estimates of Substance Use from the 2005-2006 National Surveys on Drug Use and Health. OAS series \# H-33, DHHS Publication No. (SMA) 08-4311. Rockville, MD: SAMHSA, 2008.

71. Messer K, Pierce JP. Changes in age trajectories of smoking experimentation during the California Tobacco Control Program. Am J Public Health 2010;100: 1298-306

72. Gilpin EA, Lee L, Pierce JP. How have smoking risk factors changed with recent declines in California adolescent smoking? Addiction 2005;100:117-25.

73. Pierce J. Australia's leadership role in the evolution of tobacco control programs in the United States. Health Promot J Austr 1997;7:11-17.

74. Egger G, Frape G, Mackay B. Applied problems of media use in health promotion-the North Coast experience. New Doctor 1981 January:25-9.

75. Scollo MM, Winstanley MH. Tobacco in Australia. In: Victoria CC, ed. Facts and Issues. 3rd edn. Melbourne, Australia: Cancer Council Victoria, 2008.

76. Hill D, White V, Letcher T. Tobacco use among Australian secondary students in 1996. Aust N Z J Public Health 1999;23:252-9.

77. Hill DJ, White VM, Scollo MM. Smoking behaviours of Australian adults in 1995: trends and concerns. Med J Aust 1998;168:209-13.

78. White VM, Smith G. Australian secondary school students' use of tobacco, alcohol, and over-the-counter and illicit substances in 2008. Canberra, Australia: Australian Government Department of Health and Ageing, 2009. http://www. nationaldrugstrategy.gov.au/internet/drugstrategy/Publishing.nsf/content/school08 